\title{
Social isolation shortens lifespan
}

\author{
Ageing study finds being alone is a health risk.
}

Amanda Mascarelli

25 March 2013

Scientists have long known that both social isolation and feelings of loneliness can increase risk of illness and death in people. But it has been less clear whether isolation, which can lead to loneliness, undermines health, or whether either factor, acting alone, can harm well-being. Today, researchers report in the Proceedings of the National Academy of Sciences that limited contact with family, friends and community groups predicts illness and earlier death, regardless of whether it is accompanied by feelings of loneliness ${ }^{1}$.

The scientists analysed data from 6,500 people aged 52 and older enrolled in the English Longitudinal Study of Ageing, which monitors the health, social well-being and longevity of people living in England. The researchers evaluated social isolation on the basis of the amount of contact participants reported having with family, friends and civic organizations, and they assessed loneliness using a questionnaire. They tracked sickness and mortality in study participants from 2004 to 2012.

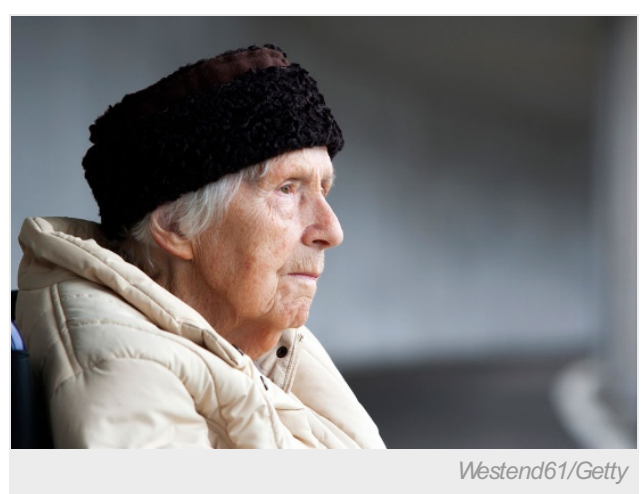

Older people reap physical and emotional benefits from social interaction.

The researchers found that social isolation was correlated with higher mortality — even after adjusting for pre-existing health conditions and socioeconomic factors — but loneliness was not.

"When we think about loneliness and social isolation, we often think of them as two faces of the same coin," says Andrew Steptoe, a psychologist and epidemiologist at University College London, who led the study. But the findings suggest that a lack of social interaction harms health whether or not a person feels lonely, he says. "When you're socially isolated, you not only lack companionship in many cases, but you may also lack advice and support from people."

The findings contradict two recent studies that suggest loneliness is associated with declining health and increased mortality in older people 2,3 . "I think it's kind of a puzzle that we now need to solve," says John Cacioppo, a psychologist at the University of Chicago in Illinois, and a co-author of one of the earlier studies. He says more work is needed to understand cultural factors that may influence results, such as differences in the way people report loneliness.

Steptoe says that he plans to examine whether social isolation affects treatment and outcomes during illness. That does not mean loneliness should be ignored, he says.

"We should make every effort to try to alleviate the loneliness of older people," says Steptoe. "But at the same time, we need to attend just to the sheer amount of social contact that people have and make sure that people do maintain their social contacts. That might be just as important."

Nature | doi:10.1038/nature.2013.12673

\section{References}

1. Steptoe, A., Shankar, A., Demakakos, P. \& Wardle, J. Proc. Natl Acad. Sci. USA http://dx.doi.org/10.1073/pnas.1219686110 (2013).

2. Luo, Y., Hawkley, L. C., Waite, L. J. \& Cacioppo, J. T. Soc. Sci. \& Med. 74, 907-914 (2012).

3. Perissinotto, C. N., Cenzer, I. S. \& Covinsky, K. E. Arch. Intern. Med. 172, 1078-1084 (2012). 